\title{
Building a Metaframework for Sustainable Transport Indicators
} Review of Selected Contributions

\section{Cornet, Yannick; Gudmundsson, Henrik}

\section{Published in:}

Transportation Research Record

Link to article, DOI:

$10.3141 / 2531-12$

Publication date:

2015

Document Version

Peer reviewed version

Link back to DTU Orbit

\section{Citation $(A P A)$ :}

Cornet, Y., \& Gudmundsson, H. (2015). Building a Metaframework for Sustainable Transport Indicators: Review of Selected Contributions. Transportation Research Record, 2531(2531), 103-112. https://doi.org/10.3141/253112

\section{General rights}

Copyright and moral rights for the publications made accessible in the public portal are retained by the authors and/or other copyright owners and it is a condition of accessing publications that users recognise and abide by the legal requirements associated with these rights.

- Users may download and print one copy of any publication from the public portal for the purpose of private study or research.

- You may not further distribute the material or use it for any profit-making activity or commercial gain

- You may freely distribute the URL identifying the publication in the public portal 


\title{
Building a Meta-Framework for Sustainable Transport Indicators - A Review of Selected Contributions
}

\author{
Yannick Cornet, Corresponding Author \\ Technical University of Denmark, Department of Transport \\ Bygningstorvet 115, DK - 2800 Kgs. Lyngby, Denmark \\ Tel: +45 2237 0457; Email: yancor@transport.dtu.dk

\section{Henrik Gudmundsson} \\ Technical University of Denmark, Department of Transport \\ Bygningstorvet 115, DK - 2800 Kgs. Lyngby, Denmark \\ Tel: +45 4525 6543; Email: hgu@transport.dtu.dk
}

Word count: 6,085 words text +3 tables/figures x 250 words $($ each $)=6,835$ words +35 references

TRR Paper number: 15-1766

March $15^{\text {th }} 2015$ 


\begin{abstract}
Several recent papers presented at TRB and elsewhere seek to make sustainability manageable. To this end they suggest using indicators and performance measures to help conceptualize and operationalize sustainability for transportation-related planning and decision-making. These studies often present frameworks that will allow sustainability indicators and measures to be included in, for example, agency strategies and practices. Moreover, some suggest criteria for selection of individual indicators and performance measures. The studies, however, do not always agree on what is really meant by a framework or how to use it for making sustainability-based decisions, and the aspects and concerns they underline tend to differ.
\end{abstract}

This paper addresses the issue of frameworks more generically and explores what the authors term a 'meta-framework' with a set of associated criteria to guide the framing of indicators for sustainable transportation. Based on an explicit framework theory, it is found that the three functions of conceptualization, operationalization and utilization provide a logical structure of complementing features for building indicator frameworks. Characteristics of robust indicator frameworks were evaluated in terms of their significance for the three key functions and collected into a list of criteria. A review of the Brundtland report provides an example of how a more finely grained understanding of sustainability can inform the conceptualization criterion 'Ranking of sustainability impacts'.

The meta-framework is primarily intended as a basis for undertaking empirical analysis and to 'meta-evaluate' existing practice frameworks with regards to the strength of the level for sustainability they are likely to provide.

Keywords: Sustainability, Transportation, Framework, Indicators, Evaluation

\title{
LIST OF TABLES
}

TABLE 1 Attributing Framework Criteria to Key Framework Functions

TABLE 2 Sustainable Transport Indicator Framework Criteria

\section{LIST OF FIGURES}

FIGURE 1 Brundtland-based Model of Sustainability 


\section{INTRODUCTION}

Despite associated complexity, it would no longer be fair to depict sustainability as a marginal or exotic concern in the assessment of transportation policies, plans, programs, or projects. On the contrary, many agencies in the US and around the globe have adopted notions of sustainability principles or goals for parts of their activities or even as a more general direction. Several recent reports, papers and guidance documents seek to make sustainability manageable by suggesting indicators and performance measures as tools to help conceptualize and operationalize sustainability for planning and decision-making. According to several studies in this field, the best approach is not to simply add a few sustainable transportation indicators (STI) to an agency's existing performance measurement system. The recommendation is rather to integrate sustainability principles and goals at the higher level of strategic planning and performance measurement and then to derive a set of indicators that serves this purpose (1-4). If successful, this approach is likely to result in a more meaningful approach to sustainability by an agency than simply parachuting in a few indicators into an otherwise unaltered practice.

These studies highlight the importance of 'framing', proposing frameworks for allowing sustainability indicators and measures to be effectively selected and included in, for example, agency strategies and practices. Some studies go a long way in typologizing different existing frameworks (1) and some suggest criteria for what should be covered in STI frameworks (2). However, the studies do not always agree about what is meant by a framework, what is assumed to be the precise role of the framework in practice, or how a framework is meant to help agencies make decisions that are actually more sustainable. Arguably, this requires that an adequate comprehension of sustainability be included in a framework from the outset, which is sometimes lacking in the frameworks currently in use $(3,5)$. However, while conceptualizing sustainability in transportation is a significant task in itself, equally important is the actual usage of indicators to ensure sustainability is integrated into key activities and actions in practice, which has been identified as a weakness for various sustainability indicator systems over the last years (6-8).

A 'meta-framework' should serve as a framework for such a comprehensive framing exercise. The meta-framework proposed here aims to span three key functions of an indicator framework, described as 1) conceptualization, 2) operationalization, and 3) utilization (9).

The approach of the paper is as follows: first, an elaboration of the notions introduced here is provided in the following Theory section. Next, the paper presents the analysis of key recent scientific studies on sustainable transportation indicator frameworks in terms of what they propose for building the meta-framework and for allocating criteria with regard to the three framework functions. The Development of the meta-framework section describes the selection of the papers, how they are analyzed, and illustrates the qualitative method used in the analysis. The main findings of the analysis are presented in Table 2. In the Criteria exemplification section, a framework criterion for 'sustainability explicitness' is used to illustrate the possibility of a deeper level of analysis. The Discussion section considers key learnings from building the framework as well as some important limitations in the proposed approach to allocate criteria to functions. The conclusion points to further work and subsequent application of the meta-framework to empirical analysis. 
The background for the paper is a Danish research project on national sustainable transport planning called SUSTAIN. This research is conducted in close collaboration with a defined 'user group' representing national agencies and consultancies in the practice field. The meta-framework presented here is, however, not intended as direct guidance for practitioners. The main aim of the meta-framework is to support empirical research in actual practices and frameworks adopted by transportation agencies, including the level of guidance the (explicit or implicit) frameworks provide in terms of the full set of framework functions. It is thus an analytic tool to 'meta-evaluate' existing practice frameworks. The resulting analysis will support the development of guidance for improving practice.

\section{THEORY}

This section briefly presents the theoretical understandings of sustainability, complexity, and indicators that generally inform this research, and then explores the notion of frameworks in more depth, before finally elaborating the three meta-framework functions.

\section{Overall Understanding}

The authors envisage sustainable transportation as embedded within the wider notion of sustainable development. The overarching aim is a comprehensive, fair and persistent improvement of human well-being, considering social, economic and environmental conditions. It thus becomes clear why measuring progress towards sustainable transportation is not trivial, as it involves highly complex interrelations between systems (e.g. transportation, economy, technology, society, environment, governance) and drivers such as quality of life and distributional considerations. These interrelations are currently not well understood; especially if a longer time horizon is adopted. When the proper measurement of progress in society as such is an ongoing topic for social and scientific debate (10), it is not to be expected that a sustainable transportation equation can easily be found. On the other hand, dealing with sustainability in transportation in a random fashion is not the solution, given the potential for further environmental degradation, and the potential societal benefits from transforming and improving the systems.

Within such a vision, measuring progress towards sustainable transportation should rely on a broad set of indicators, understood as variables selected to represent the partly 'hidden' phenomena of sustainability in transportation. They should be measurable in corresponding values and support understanding or action. Indicators can be depicted as approximations and as boundary objects (11) that can ideally act as a bridge between science and policy deliberation. It should be noted that potential risks in relying on this instrument have been identified by research, such as inadequate conceptualization, lack of resources to collect the necessary data, and non-use, symbolic use, or distorted use of indicators in decision making $(5,6)$.

\section{The Concept of 'Frameworks'}

Several comprehensive reviews such as the one by Jeon and Amekudzi (1) have shown a wide variety of frameworks in practical use for organizing sustainability indicators in some logical fashion. However, differing ideas of what a 'framework' is and its functions for measuring sustainable transportation exist in the theoretical literature. Ramani et al. (12) provide a comprehensive framework for sustainability assessment intended for direct application in US transportation agencies. Barrella et al. (13) provide a framework enabling agencies to self-assess their practices from a sustainability point of view. Jourmard et al. (4) focus on a framework for the 
construction, assessment, and use of individual indicators. Johnston (5) is more concerned with a conceptual framework supporting decision-making through indicators for analyzing and prioritizing. Marsden et al. (3) also speak of a framework for selecting (performance) indicators, but refer to the need for a wider framework for transport strategy development. Also Pei et al. (2) refer to conceptual frameworks (such as the Triple Bottom line) used for the development of sustainable transportation indicators, as well as making suggestions for a framework to develop sustainable transportation strategies. Litman (14) is one of the few providing a definition of 'indicator frameworks', understood as conceptual structures linking indicators to a theory, purpose, or planning process.

The following section combines several of these aspects, to provide a 'meta-framework' for evaluating STI frameworks.

\section{Framework Functions}

At a general level, in this paper a framework is understood as an abstraction: a type of mental and communicative construct to help build a coherent world view. A framework is not always visible to the user, but a framework for the use of indicators in a decision making context should be designed in a conscious, communicative process (15). Assmuth \& Hildén (16) define frameworks as "the conceptual and procedural constructs that assimilate, process, and give meaning to information". This definition highlights two dimensions to help frameworks do precisely this: 1) the 'conceptual' dimension that aims to capture the substance or essence of what is to be measured and elucidated (for example, frameworks to measure 'sustainability' organized in the Triple Bottom Line (TBL) domains), and 2) the 'procedural' or 'operational' dimension, which refers to more practical concerns - who needs to do what to collect, produce and report the required information?

A third important dimension not highlighted by Assmuth and Hilden's definition concerns the purpose of the information, what is termed hereon the 'utilization' function. As reported specifically for the sustainable transport assessment by Ramani et al. (12), it may not be the same types or combinations of indicators that are needed for different indicator applications, such as decision making, communication, or performance accounting. Indicators that disregard a specific utility or purpose are likely to be misinterpreted or ignored.

Conceptualization, operationalization, and utilization are adopted here as the key functions in a meta-framework for sustainable transportation indicator frameworks to be built by transportation departments or agencies $(9,17)$. In the following, the three functions used in the meta-framework are explained, then the concept of meta-framework is defined and its use is explained.

Conceptualization refers to the theoretical grounding of a framework, what De Neufville calls 'theoretical validity' (18). Conceptualization provides an opportunity for scientific and normative consistency in the process that will drive framework and indicator design. Although conceptualization is typically theory-driven, the concept of sustainability itself evokes significant normative considerations, such as taking a position on visions of desired futures, and whether, for example, to adopt a 'strong' or 'weak' interpretation of sustainability criteria $(17,19)$. Validating a framework for adequate conceptualization requires verifying that the selected sustainability theories are explicit and adequately justified. 
Operationalization refers to the practical concerns of translating concepts into practice, procedures, tools, and indicators. It builds from the theories and normative concepts elaborated in the conceptual function and considers the practical feasibility of measuring them (17). This involves, for example, manpower, costs, logistics, and data collection, as well as decisions on the structure, number, and aggregation level of indicators. This function may partly be data-driven, but should not be purely dictated by mundane practical concerns. Operationalization also requires careful analysis of whether indicators supporting a policy or a given agency action represent a stepping stone towards sustainability or not. Testing the operational validity of a framework involves primarily a concern for feasibility and instrumentality, all the while insuring a connection to the underlying concepts set forth (18).

Utilization, the third function, refers to the strategic implementation of the framework in its context of governance. It is strategic in that it refers to the linkages to the existing institutional arrangement and the various visions, strategies and goals institutions are already pursuing, and the indicators needed for different planning or management tasks. In other words, the utilization function is policy-driven: it is concerned with making indicators useful for the various planning and policy applications. Utilization could also involve indicators supporting transitions beyond existing policies (20). Underlying this function is the idea that frameworks or indicators, if not used, are of little value. Validating a framework or indicators for the utilization function involves a concern for intuitiveness, what De Neufville calls 'experiential validity' (18).

\section{Purpose of the Meta-Framework}

A meta-framework is understood as an overarching frame for what should inform the analysis and eventually the design of STI practice frameworks, meaning frameworks used by or provided for transportation policy and planning bodies to select and apply indicators for sustainable transportation. The meta-framework is not a general theory, nor a master framework to be adopted directly by agencies, but a classification and evaluation device. It should, above all, allow for a structuring of the empirical analysis of frameworks adopted by agencies in practice. Such analysis will review how the conceptual, operational and utilization functions of a case framework are performed, and how the most important criteria for each function are fulfilled. These criteria should allow a comprehensive analysis of the strengths and weaknesses of different practical frameworks with regard to how well they manage to connect sustainability theory to action.

The empirical analysis can be directly helpful for practice. A case agency could, for example, be informed that its framework embodies a limited concept of sustainability constrained by the use of an existing dataset used for project review, or that in spite of a well-integrated understanding of sustainability, it lacks a strategy for translating measured results into timely policy recommendations. Comparative analysis based on the meta-framework could identify common features and gaps, and be used as a basis for testing hypotheses regarding how indicators influence decisions on option generation, design, operation, maintenance and other aspects of transportation systems. Eventually it should help evolve sustainability measurement in transportation planning from a position as a niche, ad hoc, or add-on activity into something like an "Organizing Principle for Transportation Agencies", as it has recently been formulated (21). 


\section{DEVELOPMENT OF THE META-FRAMEWORK}

\section{Literature Selection}

The primary literature consists of articles published in the Transportation Research Record (TRR). This is complemented by selected literature that is specifically dealing with STI frameworks in other ISI journals. The selection process consisted first of a search in Elsevier's SCOPUS bibliographic database with the following keywords: ( transport* OR mobility) AND (indicator OR benchmark OR metric OR measure* OR eval*) AND ( framework) AND ( sustainab*). The focus of the review is on land transportation sustainability studies that are of interest to designing frameworks; consequently contributions focussing on a more narrow area of transport such as a single impact (e.g. noise), type (e.g. freight), mode (e.g. air), scale (e.g. a specific city), or tool (e.g. GIS) were excluded. In this iteration, larger studies, $\mathrm{PhD}$ theses, book chapters, and papers with no current citations were also excluded. Grey literature such as existing (supra-) national STI frameworks were not considered, although the analytical approach developed here could inform a complementing phase of analysis of such practice frameworks. The resulting list of reviewed papers consists of 10 TRR contributions $(2-5,12-14,22-24)$ and another 9 complementing papers $(1,9,20,25-30)$.

\section{Method}

In the review, characteristics for robust indicator frameworks were first collected and evaluated in terms of their significance for the three functions of Conceptualization - Operationalization Utilization. Because Pei et al. (2) propose the most extensive and explicit list of characteristics for an STI framework, this study is useful to illustrate the approach to build the meta-framework. The evaluation method applied is qualitative and used a scoring as illustrated in Table 1 that shows the evaluation of this reference. The fact that most criteria in this example have some relevance for all functions underlines the important observation that the functions are interrelated and cannot easily be ascribed to strictly one of the three functions. For example, conceptual choices may raise operational difficulties, utilization aspects may influence operational choices, and operational or utilization constraints may obscure or force to reconsider conceptual choices. Each criterion was allocated to the function for which it likely has most relevance.

\section{TABLE 1 Attributing Framework Criteria to Key Framework Functions}

$* * *=$ primary challenge $* *=$ has implications for $*=$ inspired or driven by factors

\begin{tabular}{|l|l|l|l|}
\hline $\begin{array}{l}\text { Key Framework Functions } \rightarrow \\
\text { / Pei et al. 2010 characteristics for robust indicator } \\
\text { framework (2) }\end{array}$ & Conceptualization & Operationalization & Utilization \\
\hline $\begin{array}{l}\text { Comprehensive, holistic and balanced view of } \\
\text { sustainability }\end{array}$ & $* * *$ & $* *$ & $*$ \\
\hline Connection to goals and objectives & $* *$ & $*$ & $* * *$ \\
\hline Vertical and horizontal integration & $*$ & $* *$ & $* * *$ \\
\hline $\begin{array}{l}\text { Capturing the effects of interactions and identifying } \\
\text { trade-offs }\end{array}$ & $*$ & $* * *$ & $* *$ \\
\hline Reflecting stakeholder perspectives & $*$ & $* *$ & $* * *$ \\
\hline $\begin{array}{l}\text { Consideration for agency and stakeholder capacity } \\
\text { and constraints }\end{array}$ & $*$ & $* *$ & $* * *$ \\
\hline Flexibility and fostering learning & $*$ & $* *$ & $* * *$ \\
\hline
\end{tabular}


Additional characteristics were extracted from reviewing the remaining papers. In this process, a 'characteristic' was accepted as a potential criterion if at least three TRR papers addressed it. Characteristics identified by less than three papers were either put aside, merged with a similar one, or included if enough support was provided by the complementing papers. Consideration was also given as to whether a characteristic was explored in-depth or simply mentioned in passing.

Finally, in order to provide examples of which features to look for when using a criterion in empirical research, the Table 2 ' $\mathrm{B}$ ' column refers to a classification system proposed by Barrella et al. (13). Barella et al. define a set of 'Internal factors' that were found to be well-matched to the meta-framework criteria and can serve as preliminary checklists for helping practioners understand what fulfilling a criterion might entail. Although these examples apply to the level of the agency in general and not necessarily specifically to performance measurement systems, they lay the groundwork for the use of such STI frameworks. Some examples and discussion of these assessment factors is given under the exemplification section for three key criteria, however not all 32 factors could be presented in detail here.

This approach led to a list of criteria, which now forms the meta-framework presented in Table 2.

\section{TABLE 2 Sustainable Transport Indicator Framework Criteria}

(*) Examples of factors to look for in existing frameworks are extracted from Barrella et al. (13).

'- ' means there were no assessment factors that could be ascribed to this criterion.

(**) References do not necessarily reflect every part of the description, but rather broadly contributed to the understanding of the criteria.

References under 'See also' refer to selected non-TRR papers.

\begin{tabular}{|c|c|c|c|c|}
\hline$\#$ & Criteria & Summary of Rationale & B.* & Refs. ** \\
\hline & \multicolumn{4}{|c|}{ Conceptualization } \\
\hline 1 & $\begin{array}{l}\text { Adopting an } \\
\text { explicit, } \\
\text { comprehensive, } \\
\text { and holistic } \\
\text { view on } \\
\text { sustainability }\end{array}$ & $\begin{array}{l}\text { Sustainability should be explicitly conceptualized, with a firm } \\
\text { grounding in sustainable development theory }(3,5) \text {. The } \\
\text { conceptualization should be comprehensive in addressing all relevant } \\
\text { factors, reflecting fundamental and non-negotiable principles of } \\
\text { sustainability }(2,12) \text {. A holistic perspective on sustainability } \\
\text { recognizes the transport system as a complex and dynamic aspect of } \\
\text { larger social, environmental, economic and governance systems }(2 \text {, } \\
\text { 12). It considers the transport system boundaries with a view to risks of } \\
\text { unintended, induced or rebound effects outside of it }(9,25) \text {. }\end{array}$ & $\begin{array}{l}\mathrm{I}-1 \\
\mathrm{I}-2 \\
(\mathrm{I}-3)\end{array}$ & $\begin{array}{l}(2,3,5 \\
12,14) \\
\text { See also } \\
(9,25 \\
29,30)\end{array}$ \\
\hline 2 & $\begin{array}{l}\text { Allowing a } \\
\text { long time } \\
\text { horizon }\end{array}$ & $\begin{array}{l}\text { The time horizon considered should be covering the long term, } \\
\text { including future generations perspectives, to allow assessment of } \\
\text { impacts affecting intergenerational equity(22). Slowly evolving } \\
\text { dynamics such as transportation/land use interactions or potential } \\
\text { health/quality of life impacts are especially relevant in long range } \\
\text { sustainability planning (3). }\end{array}$ & I-10 & $\begin{array}{l}(3,12, \\
22,25) \\
\text { See also } \\
(20,31)\end{array}$ \\
\hline 3 & $\begin{array}{l}\text { Integrating land } \\
\text { use and } \\
\text { transportation } \\
\text { on a broad } \\
\text { geographic } \\
\text { scale }\end{array}$ & $\begin{array}{l}\text { The interactions of land use and transportation should be explicitly } \\
\text { conceptualized and addressed where relevant, considering inputs and } \\
\text { outputs of land as a scarce resource that affects transportation needs } \\
\text { and planning outcomes }(22,26) \text {. This criterion is particularly } \\
\text { important to ensure that changes to urban form and travel patterns can } \\
\text { be evaluated with regards to spatial aspects of equity }(12,28) \text {. }\end{array}$ & $\begin{array}{l}\mathrm{I}-21 \\
(\mathrm{I}-4)\end{array}$ & $\begin{array}{l}(3,12, \\
14,22 \\
23) \\
\text { See also } \\
(25,26 \\
28-30)\end{array}$ \\
\hline
\end{tabular}




\begin{tabular}{|c|c|c|c|c|}
\hline 4 & $\begin{array}{l}\text { Capturing } \\
\text { interactions to } \\
\text { identify } \\
\text { trade-offs }\end{array}$ & $\begin{array}{l}\text { Recognizing the multiple points of interconnection between } \\
\text { sustainability notions over broad temporal and geographic scales is } \\
\text { necessary to identify and address potential trade-offs between } \\
\text { seemingly remote and disconnected impacts }(2,12) \text {. Trade-offs should } \\
\text { be summarized and carefully considered, not ignored or minimized }(5) \text {. }\end{array}$ & - & $\begin{array}{l}(2,5,12, \\
14) \\
\text { See also } \\
(25,29)\end{array}$ \\
\hline 5 & $\begin{array}{l}\text { Supporting } \\
\text { consistency } \\
\text { between } \\
\text { transport and } \\
\text { sustainability } \\
\text { objectives }\end{array}$ & $\begin{array}{l}\text { If consistency with sustainability objectives is not secured there is a } \\
\text { risk of 'tunnel vision effect' (3), where indicator sets are built on } \\
\text { existing or inherited policies and goals with little consideration for } \\
\text { sustainability. Transport goals and objectives should be mapped to } \\
\text { sustainability principles identified in criterion } 1 \text {. This can take the } \\
\text { form of an explicit table such as that proposed by Ramani et al. (12). }\end{array}$ & $\begin{array}{l}\mathrm{I}-5 \\
\mathrm{I}-15 \\
\mathrm{I}-16\end{array}$ & $\begin{array}{l}(3,5,12, \\
14,24)\end{array}$ \\
\hline 6 & $\begin{array}{l}\text { Ranking } \\
\text { of sustainability } \\
\text { impacts }\end{array}$ & $\begin{array}{l}\text { Determining the relative importance of various impacts associated } \\
\text { with sustainability principles while taking into account factors such as } \\
\text { irreversible effects allows a framework to deal more effectively and } \\
\text { consistently with value conflicts and trade-offs. Conceptualization } \\
\text { should include a strong, yet nuanced normative framework to allow } \\
\text { the placement of certain indicators at a higher level (5) e.g. the nested } \\
\text { model (12). The need for a refined sustainability model is further } \\
\text { discussed in the text. }\end{array}$ & $\mathrm{I}-19$ & $\begin{array}{l}(3,5,12) \\
\text { See also } \\
(28,35)\end{array}$ \\
\hline 7 & $\begin{array}{l}\text { Informing } \\
\text { strategic } \\
\text { sustainable } \\
\text { transport } \\
\text { choices }\end{array}$ & $\begin{array}{l}\text { The conceptualization should include transportation-specific } \\
\text { sustainability goals and impacts as well as strategic options and levers } \\
\text { for sustainable transport planning. This should include guidance to } \\
\text { help differentiate between higher and lower impacts of targets and } \\
\text { measures towards a sustainable transport paradigm (1). This can allow } \\
\text { for objective ways to decide among alternative policies (5). What this } \\
\text { may include is shortly introduced in the text. }\end{array}$ & $\begin{array}{l}\text { I-6 } \\
\text { I-7 } \\
\text { I-8 }\end{array}$ & $\begin{array}{l}(5,12) \\
\text { See also } \\
(1,28, \\
33)\end{array}$ \\
\hline & \multicolumn{4}{|c|}{ Operationalization } \\
\hline 1 & $\begin{array}{l}\text { Creating an } \\
\text { indicator } \\
\text { system logic } \\
\text { based on an } \\
\text { understanding } \\
\text { of linkages }\end{array}$ & $\begin{array}{l}\text { Sustainable transportation indicator systems should be designed to } \\
\text { make explicit causal chains from driving forces to final impacts }(1,22 \text {, } \\
\text { 27). Depending on the particular planning context, decision-support } \\
\text { tasks and intended indicator applications, the system logic may } \\
\text { emphasize linkages to strategic policy objectives, agency actions } \\
\text { (processes), changes (outputs), intermediate and key outcomes (goals) } \\
(2,3,12,25) \text {. Pressure - State - Response or similar root cause analysis } \\
\text { and influence diagramming tools can be used to highlight such } \\
\text { linkages }(4,25,28) \text {. }\end{array}$ & $\mathrm{I}-11$ & $\begin{array}{l}(2-5,12 \\
14,22) \\
\text { See also } \\
(1,9,25 \\
27,28)\end{array}$ \\
\hline 2 & $\begin{array}{l}\text { Supporting well } \\
\text { founded target } \\
\text { setting }\end{array}$ & $\begin{array}{l}\text { When connected to transport models and other prospective tools and } \\
\text { methods, indicators can support a process of condensing visions and } \\
\text { goals to more tangible and evidence-based targets }(3) \text {. The use of } \\
\text { forecasting models, trends interpolation, or scenarios based on long } \\
\text { term visions may allow to fix the relationship between indicators and } \\
\text { enable more effective planning to break the status-quo }(5,22) \text {. }\end{array}$ & $\mathrm{I}-13$ & $(3,5,22)$ \\
\hline 3 & $\begin{array}{l}\text { Supporting } \\
\text { integrated } \\
\text { assessment }\end{array}$ & $\begin{array}{l}\text { Decision-making based on a comprehensive view of a wide range of } \\
\text { impacts requires a mechanism for integration across indicators. } \\
\text { Aggregation or monetization are sometimes used, but bear the risk of } \\
\text { concealing meaningful data, double counting of impacts, or importing } \\
\text { hidden value judgments }(3,5,14) \text {. A cautious option is to keep outputs } \\
\text { in their natural units and avoid weighting, summing or other } \\
\text { transformations (2). Another example is the use of disaggregate } \\
\text { geographical information (GIS tools) as a way to allow assessment } \\
\text { with sensitivity to spatial scales where necessary (26). }\end{array}$ & - & $\begin{array}{l}(2,3,5, \\
14) \\
\text { See also } \\
(9,26, \\
28,29)\end{array}$ \\
\hline
\end{tabular}




\begin{tabular}{|c|c|c|c|c|}
\hline 4 & $\begin{array}{l}\text { Ensuring cost- } \\
\text { effectiveness of } \\
\text { monitoring }\end{array}$ & $\begin{array}{l}\text { Comprehensiveness is limited by the costs of data collection, which } \\
\text { implies a general requirement for data availability, timeliness } \\
\text { (including periodical updates), level of detail and ease of measurement } \\
(2-4) \text {. Coordinating the collection of common indicators is one } \\
\text { suggested approach (3). More innovative approaches may include } \\
\text { crowd-sourcing (involving the public in collecting or analyzing data, } \\
\text { such as livability measures or noise levels) and/or big data (combining } \\
\text { data from various sources such as mobile network operators and } \\
\text { transport service providers to track travel behaviors). }\end{array}$ & - & $(2-4)$ \\
\hline 5 & $\begin{array}{l}\text { Making the } \\
\text { framing process } \\
\text { explicit and } \\
\text { transparent }\end{array}$ & $\begin{array}{l}\text { Various processes have been proposed to integrate the steps in building } \\
\text { an indicator framework }(3,12) \text {. Some are mostly expert-based, while } \\
\text { others involve stakeholders or policy makers in an iterative validation } \\
\text { process. An explicit and transparent indicator framing process can be } \\
\text { expected to increase the appreciation and acceptance of the } \\
\text { information provided. }\end{array}$ & I-9 & $\begin{array}{l}3,12, \\
14,22, \\
23)\end{array}$ \\
\hline 6 & $\begin{array}{l}\text { Applying } \\
\text { indicator } \\
\text { selection } \\
\text { quality criteria }\end{array}$ & $\begin{array}{l}\text { Sustainable transportation indicators support a range of descriptive, } \\
\text { analytic, evaluative and communicative purposes. Many quality } \\
\text { criteria for individual indicator selection have been proposed, inter } \\
\text { alia: representation validity, sensitivity to changes, responsiveness to } \\
\text { trends and cumulative impacts, reliability, measurability, data } \\
\text { availability, comparability, interpretability, transparency, } \\
\text { non-corruptibility, target relevance, and actionability }(3,4,14) \text {. These } \\
\text { criteria can guide choices for selecting indicator types (nominal, } \\
\text { quantitative, qualitative), their level of aggregation (absolute, relative, } \\
\text { index) and where in the causal chain they should be placed (causes } \\
\text { versus symptoms) (19). }\end{array}$ & I-16 & $\begin{array}{l}(3,4,14, \\
22) \\
\text { See also } \\
(19,28)\end{array}$ \\
\hline & \multicolumn{4}{|l|}{ Utilization } \\
\hline 1 & $\begin{array}{l}\text { Connecting to } \\
\text { goals and } \\
\text { strategies }\end{array}$ & $\begin{array}{l}\text { A widely emphasized criterion is connecting the framework to the } \\
\text { visions, goals, and policies of the agency or sets of bodies governing } \\
\text { the transport system. This should also involve connecting it to new } \\
\text { goals adopted as part of sustainability planning processes. Long term } \\
\text { visions and scenario-based methods may help to produce more robust } \\
\text { outcomes }(5,22) \text {. This gives a rationale between agency actions and } \\
\text { desired outcomes (2). }\end{array}$ & \begin{tabular}{|l|} 
I-14 \\
I-13
\end{tabular} & $\begin{array}{l}(2,4,5 \\
12,14 \\
22,23) \\
\text { See also } \\
(25,29 \\
30)\end{array}$ \\
\hline 2 & $\begin{array}{l}\text { Integrating } \\
\text { vertically }\end{array}$ & $\begin{array}{l}\text { Tying indicator sets between different levels of agency control into a } \\
\text { common framework allows more effectiveness }(2,12) \text {. Enabling a } \\
\text { more unified framework requires both top-down and bottom-up } \\
\text { approaches, from the level of the whole agency and by specific } \\
\text { business units (12). Integrating with higher levels of governance } \\
\text { (outside an agency) into a hierarchy of plans, performance measures } \\
\text { and reporting allows to unify strategic and operational decisions in } \\
\text { support of sustainability (22). }\end{array}$ & $\begin{array}{l}\mathrm{I}-29 \\
\mathrm{I}-27 \\
\mathrm{I}-12\end{array}$ & $\begin{array}{l}(2,12 \\
22,23) \\
\text { See also } \\
(9,27- \\
29)\end{array}$ \\
\hline 3 & $\begin{array}{l}\text { Integrating } \\
\text { horizontally }\end{array}$ & $\begin{array}{l}\text { Due to the overlap of sustainability aspects across sectors and spatial } \\
\text { scales (22), interagency cooperation and coordinated reporting } \\
\text { initiatives may allow synergy in the design of more coherent policies } \\
\text { as well as managing unintended effects on other sectors (for example } \\
\text { on health or the environment) (12). }\end{array}$ & $\begin{array}{l}\mathrm{I}-22 \\
\mathrm{I}-23\end{array}$ & $\begin{array}{l}(2,12 \\
22) \\
\text { See also } \\
(9,27 \\
29)\end{array}$ \\
\hline 4 & $\begin{array}{l}\text { Engaging with } \\
\text { stakeholders } \\
\text { and context }\end{array}$ & $\begin{array}{l}\text { Taking into consideration the local context via stakeholder input is } \\
\text { considered a vital part of indicator framework development. It may } \\
\text { include debates on how best to connect monitoring with sustainable } \\
\text { transport goals }(3,12) \text { or how to connect stakeholder concepts of } \\
\text { sustainable transport with agency goals }(2) \text {. Avoiding top-down } \\
\text { predefinition also allows for stakeholder awareness and buy-in (23). }\end{array}$ & $\mathrm{I}-26$ & $\begin{array}{l}(2,3,12, \\
14,23) \\
\text { See also } \\
(9,20)\end{array}$ \\
\hline
\end{tabular}




\begin{tabular}{|c|c|c|c|c|}
\hline 5 & $\begin{array}{l}\text { Communi- } \\
\text { cating } \\
\text { externally }\end{array}$ & $\begin{array}{l}\text { To allow communication with the general public, indicator sets should } \\
\text { include measures that correspond with the public's expectations and } \\
\text { own experience (3). Indicators of progress against targets (3) or } \\
\text { indicators highlighting distributive effects may increase the relevance } \\
\text { and buy-in by politicians (5). }\end{array}$ & $\mathrm{I}-20$ & $\begin{array}{l}(3,5) \\
\text { See also } \\
(6,26)\end{array}$ \\
\hline 6 & $\begin{array}{l}\text { Aligning with } \\
\text { agency } \\
\text { capabilities and } \\
\text { constraints }\end{array}$ & $\begin{array}{l}\text { Taking into consideration the agency context in terms of mandate, } \\
\text { capabilities and constraints allows for more realistic goals and } \\
\text { measures to be established and achieved (2). It is suggested to connect } \\
\text { to specific agency focus areas and business units (12) and to consider } \\
\text { the skills required to collect and analyze data. }\end{array}$ & $\begin{array}{l}\text { I-11 } \\
\text { I-30 }\end{array}$ & $\begin{array}{l}(2,12 \\
23) \\
\text { See also } \\
(20,29)\end{array}$ \\
\hline 7 & $\begin{array}{l}\text { Leadership for } \\
\text { adapting to and } \\
\text { enabling } \\
\text { change }\end{array}$ & $\begin{array}{l}\text { Use of indicators may not automatically mean influence on policies or } \\
\text { processes }(6) \text {. Entrepreneurial, proactive and innovative leadership is } \\
\text { required to support the role of indicator frameworks towards a } \\
\text { sustainable transport paradigm }(12,23) \text {. Enablers of transition may } \\
\text { include engaging with the private sector in creating funding regimes } \\
\text { (such as public-private partnerships), investing in and experimenting } \\
\text { innovative solutions, developing partnerships for coordinating efforts } \\
\text { and building legitimacy, being opportunistic about advantageous } \\
\text { conditions for change }(22,23) \text {, and passing supportive laws }(12,22) \text {. } \\
\text { This criterion is further exemplified in the text. }\end{array}$ & $\begin{array}{l}\mathrm{I}-28 \\
\mathrm{I}-24 \\
\mathrm{I}-17 \\
\mathrm{I}-18\end{array}$ & $\begin{array}{l}(12,22, \\
23) \\
\text { See also } \\
(6)\end{array}$ \\
\hline 8 & $\begin{array}{l}\text { Providing } \\
\text { periodic } \\
\text { feedback }\end{array}$ & $\begin{array}{l}\text { Periodic feedback allows for adapting to contextual changes, } \\
\text { fine-tuning the indicator framework, fostering self-learning (2) and } \\
\text { continual improvements through the critical role of education (1). }\end{array}$ & $\begin{array}{l}\mathrm{I}-25 \\
\mathrm{I}-31 \\
\mathrm{I}-32\end{array}$ & $\begin{array}{l}(2,12 \\
23) \text { See } \\
\text { also }(1)\end{array}$ \\
\hline
\end{tabular}

\section{CRITERIA EXEMPLIFICATION}

Table 2 summarizes the rationale for all criteria, which require further explication and operationalization for empirical analysis, using relevant literature in each criterion field. It is important to avoid crude generalizations when interpreting the criteria. Unfortunately, a full discussion of each criterion is not possible here, however this section illustrates how a rich analysis could be undertaken for each criterion.

As operationalizing sustainability requires a meaningful underlying conceptualization, two criteria related to sustainability explicitness are first further explored: Ranking of sustainability impacts (criterion \#6) and Informing strategic transport choices (criterion \#7).

Pei et al. suggest a balance between the different dimensions of sustainability, without providing guidelines for achieving this balance. Marsden et al. note the "difficulty in determining the relative importance of different indicators within the monitoring framework" (3). Ramani et al. suggest that a nuanced yet strong approach to sustainability may be more desirable in providing such guidance (mentioning the possibility of viewing the traditional three dimensions of sustainability as nested circles)(12). Johnston succinctly concludes: "Some normative framework that allows the aggregation of indicators or at least the placement of certain ones at a higher level in the analysis is needed."(5) This is what criteria \#6 and \#7 of the conceptualization function convey for sustainability in general and sustainable transport, respectively.

Although providing a clear answer to this would quite likely be contested, some pathways for consideration are summarized below. 


\section{Ranking Sustainability Impacts - Revisiting the Brundtland Example}

The assessment factor from Barrella et al. provided as example for this criterion in Table 2 is "Sustainability ethic and policies are translated into concrete guidance for planning and project development" (emphasis added) (13). What form such guidance could take is illustrated here by consulting the original meaning of the concept in the Brundtland report.

In the Brundtland report, besides the oft-quoted definition of sustainable development provided, a concise alternative definition is also offered: "In essence, sustainable development is a process of change in which the exploitation of resources, the direction of investments, the orientation of technological development; and institutional change are all in harmony and enhance both current and future potential to meet human needs and aspirations" (31). This definition attests to the complexity in conceptualizing and operationalizing sustainability. However, it also encompasses the seven notions of sustainability recurrent in the report: change as an underlying process; environmental sustainability; economic and technological development; appropriate governance; the need for integrated and consistent action; expanded time perspective with concern for both the present and the long term; and the overarching social objective "to meet human needs and aspirations"(31). While this last anthropocentric concern forms the basic, normative ethics of the report, a closer reading of its 400 pages reveals a strong analytical basis and a large number of strategic implications that can inform criteria \#6 concerning the ranking of notions of sustainability.

In the report, the language used for addressing essential human needs, particularly those of the world's poor, is possibly the strongest and clearest. A number of paragraphs describe what can be called the 'paradox of poverty': how poverty is contributing to a vicious cycle of environmental degradation, health impacts and general vulnerability contributing also to further the gap between rich and poor ( $\mid 27, \uparrow 103$, Chap1.3, 1.8, 1.14, Chap2.42, Chap5.36). As a result, it is concluded that Brundtland puts present-generation human needs as primary object of concern as well as social justice (equity) within and among nations, with a clear focus on enabling poor households to meet minimum consumption standards (Chap2.26, 2.43, Chap3.7).

The report is prescriptive on the role of economic growth to combat poverty and meeting essential needs ( $\mid 28$, Chap1.49, Chap2.6, 2.29-33, 2.37). However, Brundtland does not seem to endorse the environmental Kuznets curve theory, which stipulates that as income-per-capita grows, environmental impacts first increase and then decrease in an inverted ' $U$ ' shape - on the contrary. This can be termed the 'paradox of affluence', i.e. where increased income-per-capita, past a certain point, leads to increased environmental impacts, often on a global scale and long-term in nature. While a certain level of economic growth is necessary to provide for basic human needs, beyond this Brundtland gives a prevailing commitment to preserving nature's life support systems over quantitative economic growth, calling for what the report terms the 'quality' of economic growth (Chap2.35). As a result, turning to more affluent populations, Brundtland is clear on the need to bring lifestyles and patterns of behaviour - the levels of consumption, energy and resources use - in line with the planet's ecological means with regard to long-term sustainability ( $\mid 29$, Chap1.45, Chap2.5, 2.42). This condition is refined by recognising that environmental limits depend on the state of technology, social organization, and the ability of the biosphere to absorb the effects of human activities ( $\mid 27)$. 
The report is equally prescriptive on the role of technology as with economic growth. Both are considered important means, and both face the same constraints in that the orientation of technology development must be changed to take fuller account of environmental factors (Chap2.65, 2.67). This implies that for industrialised countries such as Denmark, preserving the basic overall integrity of natural systems that support life is concluded to be a minimum requirements for SD - what Langhelle calls Brundtland's proviso of sustainability (Chap2.9) (32).

Figure 1 summarizes the overarching two priorities of sustainable development as seen from the Brundtland perspective: firstly satisfying basic human needs, and secondly safeguarding long-term ecological sustainability.

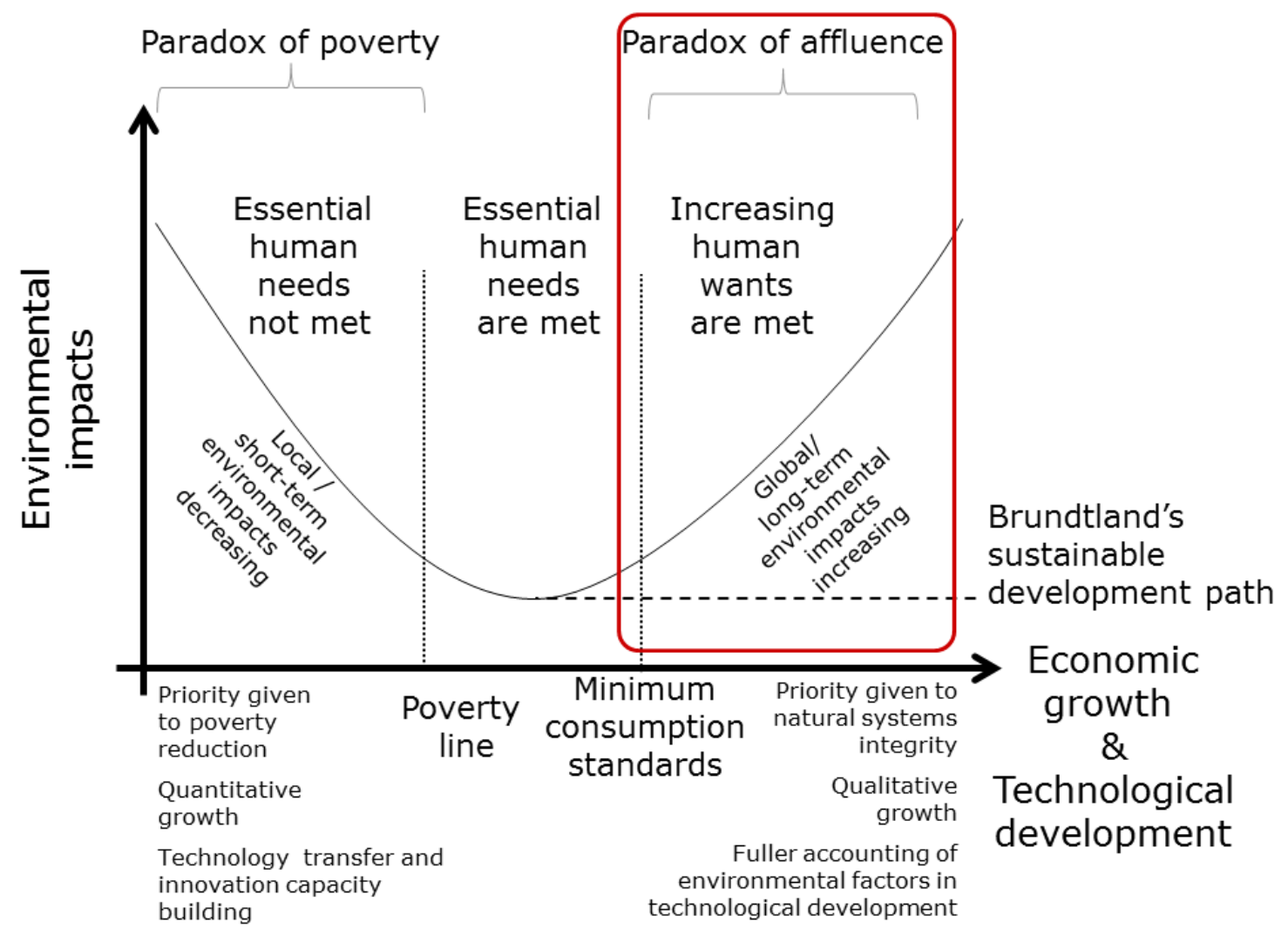

FIGURE 1 Brundtland-based Model of Sustainability - Circled in red: Denmark.

Although this initial model remains fairly high level, the seven notions of sustainability presented above are further detailed in the report, providing additional guidance for addressing and evaluating trade-offs. For example, not all environmental aspects operate within the same time or spatial scales, thus requiring that different types of natural capital command different treatment. Some, such as the protection of an endangered species and its ecosystem or a planetary boundary such as the ozone layer, indicate that some environmental protection cannot be easily traded - or substituted - by benefits in other dimensions. For achieving environmental sustainability, the report suggests each type of environmental capital be addressed strategically, namely: regeneration of renewable capital (Chap2.11), substitution of non-renewables (Chap2.12), compliance with thresholds for wastes and emissions ( $\mid 27$, Chap2.9, 2.10), precaution for irreversible capital 
(Chap2.13), and consideration for system-wide effects and integrity (Chap1.23, Chap2.11, 2.14).

Thus, a more thorough reading of the Brundtland report provides clues as to what weight, rank or status different indicators could be given in a particular context. Whereas the TBL approach would typically rank all three dimensions as equal, a Brundtland framing considers the significance of indicators by taking into account different sustainability aspects in more detail.

This is not to say that the Brundtland report ought to be the authoritative source for guiding indicator selection, aggregation or weighting towards a sustainable transport paradigm. Some of the notions presented in the report can be found in the reviewed papers. For example, Johnston raises the need and presents an overall theory of well-being as an anthropocentric basis of sustainability and, based on the concept of genuine wealth and genuine savings, is aligned with the Brundtland report on the need to more fully internalize natural capital into economic development (5). Quality of life, issues of equity within and between generations, and preserving ecological integrity are also recurrent principles $(12,14,22,25)$. However, aside from Johnston, no clear principles for prioritization or weighting are suggested, and the role of economic development is often assumed, rather than clarified as it is in the Brundtland report. Other approaches such as the Planetary Boundaries concept or the Natural Step Principles of Sustainability also exist - although they have not, as of yet, been adopted in any resolution by the United Nation's General Assembly.

From the perspective of practitioners, this exploration of criterion \#6 implies that agencies should find ways to give emphasis to indicators that are most significant from a sustainability point of view, such as ones measuring impacts on irreversible natural capital. This could for example be ensured by including these indicators among top performance indicators at the agency level, or by using them to discriminate between alternatives in connection with project selection. Overall, this highlights the importance of more refined sustainability models to guide indicator framework development and avoid the pitfalls of more simplistic representations such as the nested circles or the more common TBL.

\section{Informing Strategic Sustainable Transport Choices}

A similar conclusion can be made for conceptualization criterion \#7. Reflecting back to a complex sustainability model for indicator selection may be a far fetch for most transport agencies, hence suggesting the need for a conceptual middle layer in line with more general sustainability paradigms, theories and norms. This middle layer could consist of sustainable transport definitions, strategic levers relevant for transport policy and transport planning, goals, norms, models, lists of impacts, or actual indicators. Exploring this area further is outside the scope of this paper. Suffice to say, numerous pathways exist, such as:

- Definitions: The commonly accepted definition of Sustainable Transportation (ST) by the Center for Sustainable Transportation (CST) of Canada or its equivalent version by the European Conference of Ministers of Transport (ECMT);

- Strategies: The Avoid - Shift - Improve strategies often used (under different names) in literature;

- Paradigms: The priority given to accessibility and active modes of transport in the seminal sustainable mobility paradigm developed by Banister (33); 
- Policy Measures: The relevance of policy-packaging for creating synergy towards the implementation of sustainable transport (34);

- Norms: The general conclusion in much of the ST literature (sometimes implied, often stated) that automobile dependence ought to be addressed as first priority;

- Or the more detailed lists of ST impacts and goals expanded by authors reviewed here.

As an example of a checklist for evaluating agencies for this criterion, the following three assessment factors by Barrella et al. are proposed in Table 2: "Policies and system planning emphasize multimodal investment and integration of modes to achieve a sustainable transportation system" (assessment factor I-6); "Policies and system planning prioritize maintenance and rehabilitation of existing infrastructure" (I-7); and "Policies and system planning promote operational improvements and demand management (e.g., ITS, variable tolling, VMT reduction) over new capital investment" (I-8)(13). The emphasis is used to show how some ST-specific actions are to be prioritised over others. It is the purpose of the explicit ST conceptual middle layer suggested here to inform such prioritisation in a contextually relevant manner.

Connecting the above ST pathways more clearly to theories and principles of sustainability on one hand, and to checklists for guiding the practice on the other, would serve as areas for future research. This work has already begun, for example, Holden et al. recently revisited the Brundtland report in providing four main and secondary dimensions of sustainable development for the selection and prioritisation of passenger transport indicators (35).

\section{Leadership for Adapting to and Enabling Change}

As with the conceptualization function, the utilization function may be particularly challenging to operationalize as it relates to factors that stretch further away from the immediate concern of STI frameworks. However they are both equally relevant for the use - or non-use, as discussed earlier - of performance measures. The previous two example criteria explored qualitative considerations pointing towards defining more operational categories or checklists for the empirical phase. Here the utilization criterion \#7 Leadership for adapting to and enabling change is shortly exemplified.

The assessment factors by Barrella et al. are useful in exemplifying this criterion. One suggested factor addresses the role and importance of an agency's leadership: "Sustainability is supported by executives and managers at all levels and across units as demonstrated by performance evaluations" (assessment factor I-28). This implies that an effective STI framework should receive management support and not, for example, only exist as a 'silo' within one dedicated organization. Two more factors refer to the financial outcome of such leadership "Percentage of funds allocated for transit, bicycle, pedestrian, and other more sustainable modes" (I-17) and "Percentage of funds allocated for operating and maintaining existing infrastructure" (I-18). These factors refer both to a finer understanding of ST as discussed under the conceptualization criterion \#7 above, as well as potential revised priorities from a better informed and supportive leadership.

Developing checklists for the assessment of this criterion would require further research. For example, this could include establishing a clearer understanding of the role and commitment of managerial and political leadership, and how this impacts the use of STIs in practice. 


\section{DISCUSSION}

This section presents learnings from the experience of building the meta-framework and conclusions from the challenges that arose in this process. This relates primarily to the assumption of an existing broader transport policy or strategic process, and its relation with the indicator meta-framework.

The selected papers contribute to different functions of the meta-framework and represent various levels of ambitions with regards to sustainability and comprehensiveness. Some contribute more explicitly to the conceptualization function $(5,23)$, some to the operationalization function $(4,14)$, some to the utilization function (2), and others address more than one function $(3,12)$. The three functions intend to support this first level of categorization of the extracted criteria. However, other 'ways of seeing things' (dimensions, or lenses) also exist. For example, levels of governance differ. Where some papers clearly focus on transportation agencies (and their potential leverage), others refer to the wider process of transport governance at a more general level. Some authors define sustainability as what is achievable by a specific business unit within a transportation agency which itself belongs to a specific national context, whereas others take a helicopter view based on general principles of sustainability or ST. The literature thus indicates that there is scope to expand the meta-framework to accommodate further dimensions not considered here.

Furthermore, some authors clearly embed the indicator selection process within the higher level planning process of goal and strategy definition $(3,12)$, while others take this wider process for granted and consider it as external $(4,14)$. This raises the question: to what extent should the meta-framework tackle issues that traditionally fall outside the more practical scope of indicator selection? For utilization criterion \#1, performance measures are tying indicator selection together with goal development, which is already well demonstrated in the reviewed literature. This criterion does not require an agency indicator framework to contain guidance on creating sustainability goals per se, but it does require that such processes and commitment to plan for sustainable transportation exist. The same can be said for most conceptualization and utilization criteria, which tend to fall further outside the obvious scope of indicator frameworks. As demonstrated by the sustainability explicitness criterion, assessing those 'softer' criteria reveals the difficult task of requiring the meta-framework to provide specific assessment methods (and an accompanying grading system) for each of those.

Therefore, rather than a 'recipe' to be applied directly by agencies, the meta-framework is first and foremost a scheme for further empirical analysis of existing frameworks. The next step is to refine and apply the criteria via empirical analysis of how frameworks have been developed and used in real world conditions. Eventually this will allow for building a robust set of criteria based on theory as well as realism.

\section{CONCLUDING REMARKS}

As Banister has noted, referring to failed attempts at effectively planning for sustainable transportation, a schizophrenic path occurs when "it is clear that action is needed but no effective action is taken to remedy the solution" (33).

The assumption of this paper is that the potential role of indicator frameworks, if designed and embedded properly, will offer guidance to agency strategies and practices in bridging this 
implementation gap. By taking a perspective based on an explicit framework theory, it was found that the three functions of conceptualization, operationalization and utilization provide a logical structure of complementing features for building indicator frameworks that could support a transition towards sustainable transportation, not as a separate theoretical or practical exercise, but as part of the same process focusing also on the potential influence of indicators in decision-making and governance.

By using this approach, a review of recent contributions in the literature allowed for a collation of a set of disparate criteria into a type of meta-framework to be used in subsequent empirical analyses. The diversity of the literature jointly provides extensive guidance for creating such a framework. However, some possible improvements also presented themselves. First, the meta-framework suggests an ambitious approach if all criteria were to be fulfilled in practice. Few agencies would likely be prepared to embark on a process of building indicators with maximum fulfillment in all categories. Guidance taking into account the disparity of contexts and governance levels would be helpful to make priorities in this respect, and the empirical analysis will explore how agencies are meeting this challenge.

Secondly, criteria were found to have implications for more than one function, and it would be useful to explore this interaction further in empirical studies of agency practice. One example is the potential 'clash' between more ideal theory-based conceptualizations versus the implications for indicator systems from strongly utilization-focused policy applications (such as innovation or green economy initiatives).

Thirdly, an observation previously observed in the literature; namely that effective indicator systems are likely to be the ones that emerge from strategic sustainability planning, rather than from mere indicator building exercises. Such a strategic context should likely provide stronger support to conceptualization as well as to utilization, and should also bolster efforts to attract manpower and funding to the operational function.

In this context, conceptualization must be seen as a potentially significant element in building a system that supports decision making grounded in sustainability, rather than simply mapping out a possible topics for measurement. Empirically examining to what extent agencies are making use of the strong decision-support capacities embedded in the original concepts of sustainability and sustainable transportation should become a key theme.

The meta-framework is thus proposed as a foundation for future empirical work within the scope of the SUSTAIN project in collaboration with international research partners.

\section{ACKNOWLEDGMENTS}

The authors are grateful to the Strategic Research Council of Denmark (Innovationsfonden) that is supporting the SUSTAIN research project. The authors wish to thank SUSTAIN project partners, user group, as well as colleagues at the Technical University of Denmark and Copenhagen Business School for valuable discussions and inspiration. The authors also wish to thank four anonymous reviewers for their insight and helpful comments. 


\section{REFERENCES}

1. Jeon, C. M., and A. Amekudzi. Addressing Sustainability in Transportation Systems: Definitions, Indicators, and Metrics. Journal of Infrastructure Systems, Vol. 11, No. 1, Mar. 2005, pp. 31-50.

2. Pei, Y. L., A. a. Amekudzi, M. D. Meyer, E. M. Barrella, and C. L. Ross. Performance Measurement Frameworks and Development of Effective Sustainable Transport Strategies and Indicators. Transportation Research Record: Journal of the Transportation Research Board, No. 2163, Dec. 2010, pp. 73-80.

3. Marsden, G., C. Kelly, and C. Snell. Selecting Indicators for Strategic Performance Management. Transportation Research Record: Journal of the Transportation Research Board, No. 1956, Jan. 2006, pp. 21-29.

4. Joumard, R., H. Gudmundsson, and L. Folkeson. Framework for Assessing Indicators of Environmental Impacts in the Transport Sector. Transportation Research Record: Journal of the Transportation Research Board, No. 2242, Dec. 2011, pp. 55-63.

5. Johnston, R. A. Indicators for Sustainable Transportation Planning. Transportation Research Record: Journal of the Transportation Research Board, No. 2067, Dec. 2008, pp. 146-154.

6. Gudmundsson, H., and C. Sørensen. Some use - Little influence? On the roles of indicators in European sustainable transport policy. Ecological Indicators, No. 35, 2013, pp. 43-51.

7. Lyytimäki, J., P. Tapio, V. Varho, and T. Söderman. The use, non-use and misuse of indicators in sustainability assessment and communication. International Journal of Sustainable Development \& World Ecology, Vol. 20, No. 5, Oct. 2013, pp. 385-393.

8. Hezri, A. a., and S. R. Dovers. Sustainability indicators, policy and governance: Issues for ecological economics. Ecological Economics, Vol. 60, No. 1, Nov. 2006, pp. 86-99.

9. Gudmundsson, H. Sustainable transport and performance indicators. No. 20, 2004, pp. 3564.

10. Stiglitz, J. E., A. Sen, and J.-P. Fitoussi. Report by the Commission on the Measurement of Economic Performance and Social Progress (2009). SSRN Electronic Journal, 2010.

11. Turnhout, E., M. Hisschemöller, and H. Eijsackers. Ecological indicators: Between the two fires of science and policy. Ecological Indicators, Vol. 7, No. 2, Apr. 2007, pp. 215-228.

12. Ramani, T., J. Zietsman, H. Gudmundsson, R. Hall, and G. Marsden. Framework for sustainability assessment by transportation agencies. Transportation Research Record: Journal of the Transportation Research Board, No. 2242, 2011, pp. 9-18.

13. Barrella, E. M., A. A. Amekudzi, and M. D. Meyer. Evaluating Sustainability Approaches of Transportation Agencies Through a Strengths, Weaknesses, Opportunities, and Threats Framework. Transportation Research Record: Journal of the Transportation Research Board, No. 2357, Dec. 2013, pp. 41-49.

14. Litman, T. Developing Indicators for Comprehensive and Sustainable Transport Planning. Transportation Research Record: Journal of the Transportation Research Board, No. 2017, Dec. 2007, pp. 10-15.

15. Innes, J. Information in communicative planning. Journal of the American Planning Association, 1998.

16. Assmuth, T., and M. Hildén. The significance of information frameworks in integrated risk assessment and management. Environmental Science \& Policy, Vol. 11, No. 1, Feb. 2008, pp. 71-86.

17. Sørensen, C. H., H. Gudmundsson, and S. Leleur. National sustainable transport planning 
- concepts and practice. 2013.

18. De Neufville, J. I. Validating policy indicators. Policy Sciences, Vol. 10, No. 2-3, Dec. 1978, pp. $171-188$.

19. Joumard, R., and H. Gudmundsson. Indicators of environmental sustainability in transport. 2010 .

20. Gudmundsson, H., A. Wyatt, and L. Gordon. Benchmarking and Sustainable Transport Policy: Learning from the BEST Network. Transport Reviews, Vol. 25, No. 6, Nov. 2005, pp. 669-690.

21. Transportation Research Board of the National Academies. NCHRP Report 750 Volume 4: Sustainability as an Organizing Principle for Transportation Agencies. 2014, p. 257.

22. Amekudzi, A. A., L. Thomas-Mobley, and C. Ross. Transportation Planning and Infrastructure Delivery in Major Cities and Megacities. Transportation Research Record: Journal of the Transportation Research Board, No. 1997, Jan. 2007, pp. 17-23.

23. Maurer, L., and T. Mansfield. Blueprint for Sustainability. Transportation Research Record: Journal of the Transportation Research Board, No. 2357, 2013, pp. 13-23.

24. Mansfield, T. J., and A. M. Hartell. Institutionalizing Sustainability at the Level of State Departments of Transportation. Transportation Research Record: Journal of the Transportation Research Board, No. 2271, Dec. 2012, pp. 9-18.

25. Richardson, B. C. Sustainable transport: analysis frameworks. Journal of Transport Geography, Vol. 13, No. 1, Mar. 2005, pp. 29-39.

26. Bertolini, L., F. le Clercq, and L. Kapoen. Sustainable accessibility: a conceptual framework to integrate transport and land use plan-making. Two test-applications in the Netherlands and a reflection on the way forward. Transport Policy, Vol. 12, No. 3, May 2005, pp. 207-220.

27. Gudmundsson, H. Making concepts matter: sustainable mobility and indicator systems in transport policy. International Social Science Journal, Vol. 55, No. 176, Jun. 2003, pp. 199217.

28. Black, J., A. Paez, and P. Suthanaya. Sustainable urban transportation: performance indicators and some analytical approaches. Journal of Urban Planning and Development, Vol. 128, No. 4, 2002, pp. 184-192.

29. Marsden, G., and C. Snell. The role of indicators, targets and monitoring in decision-support for transport. European Journal of Transport and Infrastructure Research, Vol. 9, No. 3, 2009, pp. 219-236.

30. Meunier, D. Towards a Sustainable Development Approach in Transport Assessment. Procedia - Social and Behavioral Sciences, Vol. 48, Jan. 2012, pp. 3065-3077.

31. World Commission on Environment and Development (WCED). Our Common future. http://www.un-documents.net/wced-ocf.htm. Accessed Feb. 14, 2013.

32. Langhelle, O. Sustainable Development: Exploring the Ethics of Our Common Future. International Political Science Review, Vol. 20, No. 2, Apr. 1999, pp. 129-149.

33. Banister, D. The sustainable mobility paradigm. Transport Policy, Vol. 15, No. 2, Mar. 2008, pp. 73-80.

34. Givoni, M. Addressing transport policy challenges through Policy-Packaging. Transportation Research Part A: Policy and Practice, Nov. 2013.

35. Holden, E., K. Linnerud, and D. Banister. Sustainable passenger transport: Back to Brundtland. Transportation Research Part A: Policy and Practice, Vol. 54, Aug. 2013, pp. $67-77$. 